3 Research Square

\title{
Energy-Based Approach for the Analysis of a Vertically Loaded Pile in Multi-layered Non-linear Soil Strata
}

\section{Prakash Ankitha Arvan ( $\sim$ parvan2018@fau.edu )}

Florida Atlantic University https://orcid.org/0000-0002-8573-2061

\section{Madasamy Arockiasamy}

Florida Atlantic University

\section{Research Article}

Keywords: Piles, Multi-layered soil, Soil non-linearity, Analytical solutions, Vertical (Axial) load, Pile displacement, MATLAB R2019a, ANSYS 2019R3

Posted Date: November 30th, 2021

DOI: https://doi.org/10.21203/rs.3.rs-337774/v1

License: (c) (i) This work is licensed under a Creative Commons Attribution 4.0 International License.

Read Full License 
ORCID: 0000-0002-0249-7394

ORCID: 0000-0002-8573-2061

$\underline{\text { arockias@fau.edu }}$

\title{
linear Soil Strata
}

\author{
Arvan Prakash Ankitha ${ }^{1}$, M. ASCE, Madasamy Arockiasamy ${ }^{2}$, PhD., P.E., P.Eng., F. ASCE
}

${ }^{1}$ Doctoral Research Scholar, Department of Civil, Environmental and Geomatics Engineering, Florida Atlantic University, Boca Raton, FL 33431-0991, USA. Email: parvan2018@fau.edu

${ }^{2}$ Professor and Director, Center for Infrastructure and Constructed Facilities, Department of Civil, Environmental and Geomatics Engineering, Florida Atlantic University, Boca Raton, FL 33431-0991, USA. Email:

11 Abstract

12 Numerous studies have been reported in published literature on analytical solutions for a vertically loaded pile installed 13 in a homogeneous single soil layer. However, piles are rarely installed in an ideal homogeneous single soil layer. This 14 study presents an energy-based approach to obtain displacements in an axially loaded pile embedded in multi-layered 15 soil considering soil non-linearity. A simple power law based on published literature is used where the soil is assumed to be nonlinear-elastic and perfectly plastic. A Tresca yield surface is assumed to develop the soil stiffness variation

17 with different strain levels that defines the non-linearity of the soil strata. The pile displacement response is obtained 18 using the software MATLAB R2019a and the results from the energy-based method are compared with those obtained from the field test data as well as the finite element analysis based on the software ANSYS 2019R3. It is observed

20 that the results obtained from the energy-based method are in better agreement with the field measured values than 21 those obtained from the FEA. The approach presented in this study can be extended to piles embedded in multi-layered

22 soil strata subjected to different cases of lateral loads as well as the combined action of lateral and axial loads.

23 Furthermore, the same approach can be extended to study the response of the soil to group piles.

\section{Keywords}



R2019a; ANSYS 2019R3.

Declarations

Funding Not applicable

\section{Conflicts of interest/Competing interests Not applicable}

Availability of data and material Not applicable

\section{Code availability Not applicable}

Author's contributions Not applicable

\section{Acknowledgements}

34 The authors acknowledge the support received from the Florida Department of Transportation Grant: DOT-RFP-209069-CA and Florida Atlantic University for providing the senior author with the Presidential Fellowship to successfully finish this study.

\section{$37 \quad 1$ Introduction}

Many studies are available in the literature that explains the pile deformation response under different loading conditions with the pile embedded in multi-layered soil, which treat the soil as linear elastic. However, for practical applications to the real world, it is important to study the response of the non-linear behavior of the soil and the variation of soil stiffness based on its stress and strain levels. A discretized continuum approach (numerical method) or the energy-based method is preferred over the beam-on-elastic foundation approach since the approach considers the surrounding soil behavior in three dimensions: vertical, radial and circumferential directions. Several researchers estimated the pile deformations based on the energy-based method [Poulos 1971a, Poulos 1971b, Banerjee and Davies 1978, 16, Basack and Dey 2012, Georgiadis et al. 2013, Verrujit and koojiman 1989, Basu et al. 2008]. There are many numerical methods available in the published literature with various pile geometry and constitutive models using Finite Element Method [Randolph 1981, Brown et al. 1989, Trochanis et al. 1991, Carter and Kulhawy 1992, Bransby and Springman 1996, Bransby 1999]; Finite Difference Method [Ng and Zhang 2001, Klar and Frydman 2002, Basu et al. 2008, Basu et al. 2008, Haldar and Babu 2012]; and Boundary Element Method [Banerjee and Davies 1978, 
Budhu and Davies 1988, Basack and Dey 2011, Basack and Dey 2012]. The present study is based on the Finite

51 Difference method since it yields results faster when compared to the Finite Element Method.

\section{$52 \quad$ Linear Elastic Soil Model}

53 An analytical solution based on the energy-based method was used by several researchers [Vlasov and Leont'ev 1966,

54 Vallabhan and Das 1991a, Basu and Salgado 2007, Basu et al. 2008, Basu et al. 2008, Basu et al. 2009, Seo and Prezzi

55 2007, Seo et al. 2009] to estimate laterally loaded and axially loaded pile deformation for linear elastic soil.

56 Independent functions describing the soil displacement have been used; these functions vary in vertical, radial and

57 circumferential directions. The linear elastic analysis has been developed by employing variational principles and

58 minimization of energy, called Hamilton's principle, to derive the governing equation and boundary conditions.

59 Hamilton's equation can be expressed as

60

$$
\int_{t_{1}}^{t_{2}}(\delta T-\delta U) d t+\int_{t_{1}}^{t_{2}} \delta W d t
$$

61

where $T$ and $U$ are the kinetic and potential energies of the pile and soil and $W$ is the work done by the applied load,

$62 t_{1}$ and $t_{2}$ are the initial and final times of loading [Asik and Vallaban 2001].

63 The governing equations for pile deflection are obtained by minimizing kinetic and potential energies. These

64 governing equations can be solved either numerically or analytically for a given set of boundary conditions. Each of

65 the displacement components are expressed as a multiplication of one-dimensional functions when minimizing the

66 energy to obtain a set of one-dimensional equation. These equations are solved numerically using the finite difference

67 technique. In these studies, the soil is treated as linear elastic where the shear modulus $G$ and the Lame's constant $\lambda$

68 are treated as constants for all the layers [Fidel 2014].

70 In order to consider the non-linear effect of soil, the soil moduli $G$ and $\lambda$ are assumed to vary in radial, circumferential

71 and vertical directions according to the strain and stress levels [Basu et al. 2008]. The stress and strain decay with

72 increasing distances in the radial direction accomapnied by an increase in soil stiffness $G$. In other words, soil stiffness

73 degrades with increasing strain and hence it varies in both radial and vertical directions. The analysis of the soil

74 behavior using a single constitutive model is very idealistic since the undrained strength of soil depends on a number 
75 of factors such as the soil anisotropy, failure mode, strain rate, stress paths and the mode of loading effects of stress76 strain non-linearity which make the undrained strength dependent on the test type [Koutsoftas and Ladd 1985,

77 Kulhawy and Mayne 1990]. Consideration of the non-linear soil behavior will be more realistic in the analysis of pile

78 displacement response. For piles subjected to external loads, the decay of the soil stiffness varies with strain which in

79 turn depends on the type of the soil. The stiffness of soil was high at a very small strain level and decreases with the 80 increase in the strain [Atkinson 2000]. Many reasearchers [Jardine et al. 1984, Burland 1990, Atkinson and Sallfors

81 1991, Houlsby and Wroth 1991, Osman et al. 2007, Osman et al. 2007] conducted triaxial tests and reported high

82 values of soil stiffness when the shear strains are less than $10^{-5}$. Several factors including the mean effective stress,

83 void ratio, stress history, rate of loading, soil plasticity for silts and clays, stress anisotropy for sands and the effective

84 confining stress affect the small strain stiffness $G_{\max }$ [Frnevich and Massarsch 1979, Hardin and Drnevich 1972, Hardin

85 1978, Presti et al. 1996, Vucetic 1994, Yamashita et al. 2003]. The decay of the soil stiffness with the increase of 86 strain levels can be defined using the power law [Bolton and Whittle 1999, Bolton et al. 1993, Gunn 1992].

This paper presents an energy-based approach to study the displacement profile of a vertically loaded pile in multi-layered soil strata considering the soil non-linear behavior. A simple power law is used by Gunn [Gunn 1993] where the soil is assumed to be nonlinear-elastic and perfectly plastic. A Tresca yield surface is assumed to develop

90 the soil stiffness variation with different strain levels that defines the non-linearity of the soil strata. The pile 91 displacement response is obtained using the software MATLAB R2019a. The results from the energy-based method 92 are compared with those from the field test data as well as the finite element analysis based on the software ANSYS 93 2019R3. The results from the energy-based method are in good agreement with both the field test data and the finite 94 element analysis.

\section{Problem Definition}

An axially loaded pile in an isotropic non-linear elastic multilayered soil medium is shown in Fig. 1. This study

97 considers a pile of length $L$ with circular cross section of radius $r_{0}$. The pile is embedded in $n$ horizontal soil layers and is subjected to an axial (vertical) load $P_{t}$. The horizontal soil layers extend to infinity in the radial direction and the bottom $\mathrm{n}^{\text {th }}$ layer extends to infinity in the vertical direction. 


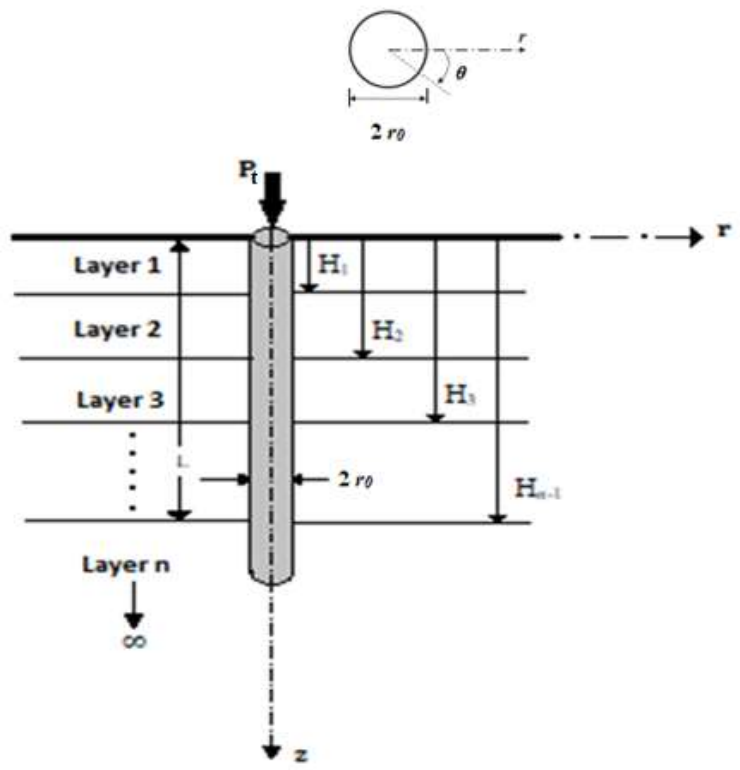

Fig. 1 An axially loaded pile in an isotropic nonlinear elastic medium

102 The terms $H_{1}, H_{2}, H_{3} \ldots H_{n-1}$ denote the vertical height from the ground surface to the bottom of any layer $i$. Therefore, 103 the thickness of any layer $i$ is $H_{i}-H_{i-1}$ with $H_{0}=0$. Due to the axisymmetric problem behavior, a system of cylindrical coordinates $(r-\theta-z)$ is chosen with the origin coinciding with the center of the pile cross section at the pile head and the $z$ axis coinciding with the pile axis. The pile head is considered to be free and the tip of the pile is clamped. Another important assumption to be noted is that there is no slippage or separation between the pile and the surrounding soil and between soil layers. The stresses and the displacement within a soil continuum are shown below in Fig. 2 (a) and (b).

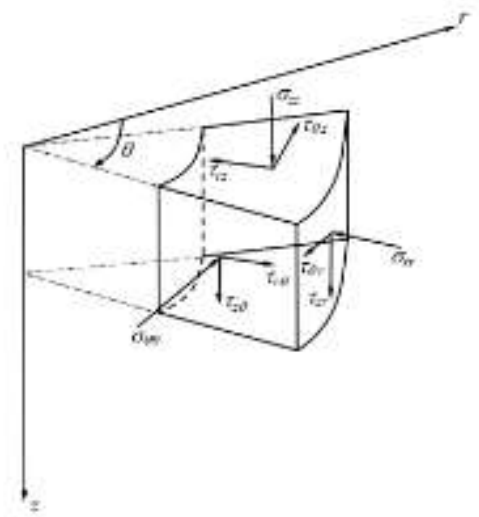

(a) Stresses within a soil continuum 


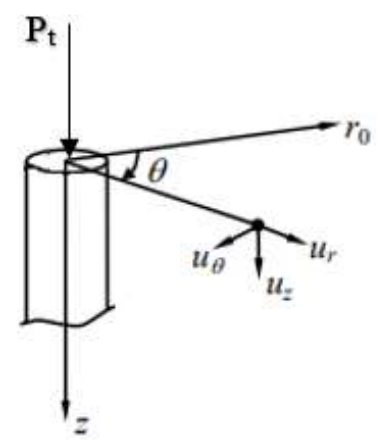

(b) Displacement within a soil continuum

Fig. 2 Stresses and displacements within a soil continuum

114 At each point in the soil domain, $G$ and $\lambda$ have been calculated (Fig. 3).

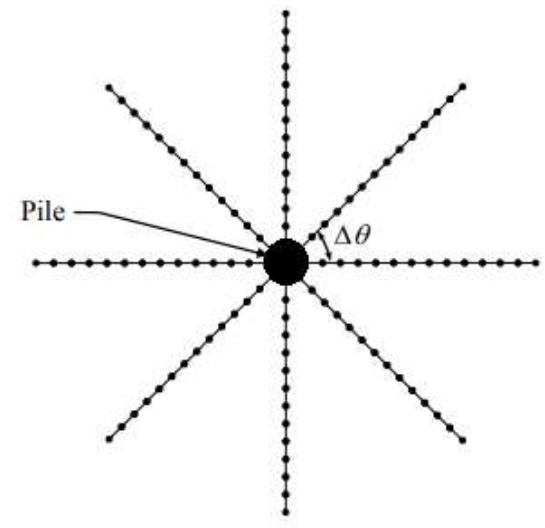

(a) Plan

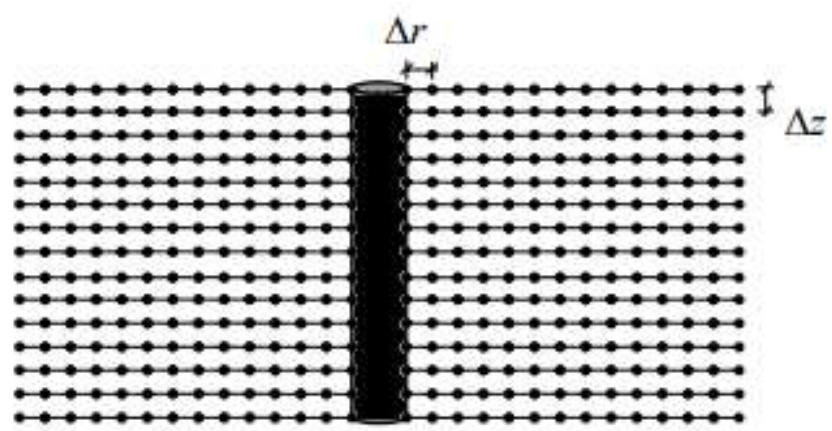

(b) Elevation

Fig. 3 Discretization of the soil (adapted from Basu et al. 2008) 
The goal of the analysis is to obtain pile head deflection caused by the action of the vertical load $P_{t}$ at the pile head.

\subsection{Basic assumptions of an axially loaded pile in multi-layered soil}

122 For an axially loaded pile, the horizontal and tangential displacements can be neglected as they are accompanied by very small strains [Salgado et al. 2007]. For the case of a pile with circular cross-section there are two functions to be

124 considered: $v(z)$ which will represent the vertical displacement at depth $z$ and the dimensionless functions $\phi(r)$ 125 describing the variation of soil displacements in the radial direction.

The vertical displacement at any point of the soil is represented as a function in $(r, z)$ :

$$
\begin{gathered}
v_{r}=0 \\
v_{\theta}=0 \\
v_{z}(r, z)=\phi(r) v(z)
\end{gathered}
$$

For a given uniform cross-sectional area of the pile along the length, $\phi(r)=1$ when $r=0$ to $r_{0}$, while $\phi(r)=0$ when $r \rightarrow \infty$. This explains the decay of the function $\phi(r)$ with an increase in the radial direction.

\section{Governing Differential Equation}

The pile and its surrounding elastic medium are subjected to a vertical displacement of the pile soil system when it is acted upon by a vertical load. The total potential energy of the pile and the soil is a summation of internal potential energy and external potential energy [Basu et al. 2008], which is given as:

$$
\Pi=\frac{1}{2} E_{p} A_{p} \int_{0}^{L}\left(\phi \frac{d v}{d z}\right)^{2} d z+\frac{1}{2} \int_{0}^{L} \int_{0}^{2 \pi} \int_{r_{0}}^{\infty} \sigma_{i j} \varepsilon_{i j} r d r d \theta d z+\frac{1}{2} \int_{L}^{\infty} \int_{0}^{2 \pi} \int_{0}^{\infty} \sigma_{i j} \varepsilon_{i j} d r-v P_{t a t z=0}
$$

137 Where $E_{p}$ denotes the elastic Young modulus of the pile, $A_{p}$ denotes the cross-section of the pile, $v$ represents the vertical displacement, $P_{t}$ is the vertical load and $\sigma_{i j}, \varepsilon_{i j}$ are stress and strain components respectively. The first term

139 of the equation represents potential pile energy, the second and third terms are potential energy from the surrounding 140 soil and the soil below the pile respectively. medium are idealized by the following relationships. The stress-strain relationship is expressed as: 


$$
\left[\begin{array}{c}
\sigma_{r} \\
\boldsymbol{\sigma}_{\theta} \\
\boldsymbol{\sigma}_{z} \\
\boldsymbol{\tau}_{r \theta} \\
\boldsymbol{\tau}_{r z} \\
\boldsymbol{\tau}_{\theta z}
\end{array}\right]=\left[\begin{array}{cccccc}
\lambda+2 G & \lambda & \lambda & \mathbf{0} & \mathbf{0} & \mathbf{0} \\
\lambda & \lambda+2 G & \lambda & \mathbf{0} & \mathbf{0} & \mathbf{0} \\
\lambda & \lambda & \lambda+2 \boldsymbol{G} & \mathbf{0} & \mathbf{0} & \mathbf{0} \\
\mathbf{0} & \mathbf{0} & \mathbf{0} & \boldsymbol{G} & \mathbf{0} & \mathbf{0} \\
\mathbf{0} & \mathbf{0} & \mathbf{0} & \mathbf{0} & \boldsymbol{G} & \mathbf{0} \\
\mathbf{0} & \mathbf{0} & \mathbf{0} & \mathbf{0} & \mathbf{0} & \boldsymbol{G}
\end{array}\right]\left[\begin{array}{c}
\varepsilon_{r} \\
\varepsilon_{\theta} \\
\varepsilon_{z} \\
\gamma_{r \theta} \\
\gamma_{r z} \\
\gamma_{\theta z}
\end{array}\right]
$$

where $G$ and $\lambda$ are the elastic constants of the soil. The strain-displacement relationship is given by:

$$
\left[\begin{array}{c}
\varepsilon_{r} \\
\varepsilon_{\theta} \\
\varepsilon_{\mathrm{z}} \\
\gamma_{r \theta} \\
\gamma_{r z} \\
\gamma_{\theta z}
\end{array}\right]=\left[\begin{array}{c}
-\frac{\partial \mathrm{u}_{\mathrm{r}}}{\partial \mathrm{r}} \\
-\frac{u_{r}}{r}-\frac{1}{r} \frac{\partial \mathrm{u}_{\theta}}{\partial \theta} \\
-\frac{\partial \mathrm{u}_{\mathrm{z}}}{\partial \mathrm{z}} \\
-\frac{1}{r} \frac{\partial \mathrm{u}_{\mathrm{r}}}{\partial \theta}-\frac{\partial \mathrm{u}_{\theta}}{\partial \mathrm{r}}+\frac{u_{\theta}}{r} \\
-\frac{\partial \mathrm{u}_{\mathrm{z}}}{\partial \mathrm{r}}-\frac{\partial \mathrm{u}_{\mathrm{r}}}{\partial \mathrm{z}} \\
-\frac{1}{r} \frac{\partial \mathrm{u}_{\mathrm{z}}}{\partial \theta}-\frac{\partial \mathrm{u}_{\theta}}{\partial \mathrm{z}}
\end{array}\right]=\left[\begin{array}{c}
0 \\
0 \\
-\phi(r) \frac{d v(\mathrm{z})}{d z} \\
0 \\
-v(z) \frac{d \phi(r)}{d r} \\
0
\end{array}\right]
$$

147 By substituting Equation (7) into Equation (6), the strain energy density function $W=\frac{\sigma_{i j} \varepsilon_{i j}}{2}$ is obtained, where the 148 summation implies the repetition of the indices $i$ and $j$ as required in indicial notation:

$$
\frac{1}{2} \sigma_{i j} \varepsilon_{i j}=\frac{1}{2}\left[(\lambda+2 G)\left(\phi \frac{d v}{d z}\right)^{2}+G\left(v \frac{d \phi}{d r}\right)^{2}\right]
$$

Substituting Equation (8) into Equation (5) and integrating with respect to $\theta$, the potential energy equation becomes:

The variational principle has been used to calculate the potential energy $\delta U$ and the external energy $\delta W$ [Vallabhan and Mustafa 1996, Lee and Xiao 1999]. As a result, the governing equations of the pile-soil system are obtained by minimizing the potential energy of soil and pile. The expression of potential energy contains different functions, such as $v(z), \phi(r), \frac{d v(z)}{d z}$ and $\frac{d \phi(r)}{d r}$, so by minimizing the potential energy gives

$$
\delta \Pi=\left[A(v) \delta v+B(v) \delta\left(\frac{d v}{d z}\right)\right]+[C(\phi) \delta \phi]
$$

where $A, B$ and $C$ are the terms associated with variations $\delta v, \delta\left(\frac{d v}{d z}\right)$ and $\delta \phi$. 
The variation of equation (9) becomes

160

161

$\delta \Pi=\frac{1}{2} E_{p} A_{p} \int_{0}^{L} \phi \frac{d v}{d z} \delta \phi \frac{d v}{d z} d z+\pi \int_{0}^{L} \int_{r_{o}}^{\infty}\left((\lambda+2 G)\left(\phi \frac{d v}{d z} \delta \phi \frac{d v}{d z}\right)+G\left(v \frac{d \phi}{d r} \delta v \frac{d \phi}{d r}\right)\right) r d r d z+\pi \int_{L}^{\infty} \int_{0}^{\infty}((\lambda+$

$\left.2 G)\left(\phi \frac{d v}{d z} \delta \phi \frac{d v}{d z}\right)+G\left(v \frac{d \phi}{d r} \delta v \frac{d \phi}{d r}\right)\right) r d r d z-v P_{\text {tat }(z=0)}$

\section{Output Parameters}

\section{(i) Pile Displacement}

The governing equation of the pile is obtained for $0<z<L$ by collecting terms associated with $\delta v d z, \delta \frac{d v}{d z} d z$ and its derivative, $\delta v$ and $\delta \frac{d v}{d z} d z \neq 0$. The governing equation is obtained as follows:

$$
k \frac{d^{2} v}{d z^{2}}+C \frac{d v}{d z}+m v=0
$$

where

$$
\begin{gathered}
C=2 \pi \int_{r_{0}}^{\infty} r\left[(\lambda+2 G) \phi^{2}\right] d r \\
k=E_{p} I_{p}+2 \pi \int_{r_{0}}^{\infty} r\left[(\lambda+2 G) \phi^{2}\right] d r \\
m=-2 \pi \int_{r_{0}}^{\infty} r G\left(\frac{d \phi}{d r}\right)^{2} d r
\end{gathered}
$$

For this study, the tip of a pile is assumed to be clamped, which means that the displacement and the curvature are equal to zero at the base of the pile. The boundary conditions are obtained by collecting $\delta v$ and $\delta \frac{d v}{d z}$. At the head of the pile $(z=0)$ :

$$
-E_{p} A_{p}-2 \pi \int_{r_{0}}^{\infty} r\left[\lambda+G\left(2+\phi^{2}\right)\right] d r \frac{d v}{d z}+P_{t}=0
$$

The displacement at the tip of the pile $(z=L)$ :

$$
v=0
$$

The second order differential equation (12) can be solved using a central finite difference scheme. Equation (12) becomes 
180 where $i$ denotes the $i^{\text {th }}$ node in $z$ direction, and $\Delta z$ is the distance between two nodes. This discretized analysis is then 181 solved using the software MATLAB R2019a.

182

183

184

\section{(ii) Soil Displacement}

The governing equation of the soil is obtained for $r_{0} \leq r \leq \infty$ by collecting terms associated with $\delta \phi d r$ :

$$
r \frac{d^{2} \phi}{d r^{2}}+\gamma_{1} \frac{d \phi}{d r}+\gamma_{2} \phi=0
$$

where

$$
\gamma_{1}=\frac{\int_{0}^{L} G+r G}{\int_{0}^{L} G}
$$

$$
\gamma_{2}=\frac{-\int_{0}^{L}(\lambda+2 G)\left(\frac{d v}{d z}\right)^{2}}{\int_{0}^{L} G v^{2}}
$$

Similar to the solution of Equation (12) by the central finite difference scheme, the governing differential equation (19) is also solved using the finite difference method (using the software MATLAB R2019a).

\subsection{Soil non-linearity}

The variation of the shear stress with strain can be described using two parameters $A$ and $n$ that have been obtained experimentally using a pressuremeter test as shown in the equation below:

$$
q=A\left(\varepsilon_{q}\right)^{n}
$$

Where $q$ represents the equivalent shear stress, $\varepsilon_{q}$ is the deviator shear strain. Atkinson (2000) shows that the decay curves of the soil stiffness with strain can be divided into three regions as shown in Fig. 4. The first region in Fig. 4 represents the very small strain where the stiffness, $G_{0}$ is constant, the second region comprising small strains starts from $\varepsilon_{0}$ till $\varepsilon=0.1 \%$ and the third region exceeds $\varepsilon=0.1 \%$ indicative of large strains. 


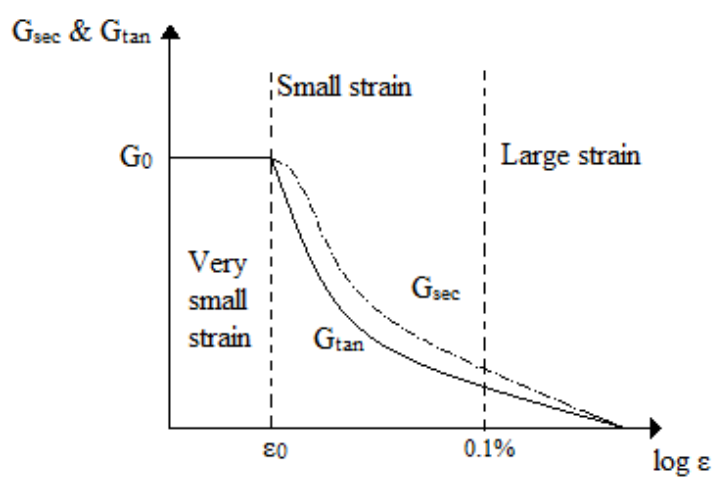

Fig. 4 The variation of normalizing shear secant with logarithmic strain $\varepsilon_{q}$ or normalized displacement (adapted from Atkinson, 2000)

In the second region the stiffness decays rapidly and in the third region with large strain levels, the stiffness is the smallest, which concludes that the soil stiffness is high at small strain and decreases with large strain [Atkinson 2000].

Fig. 5 shows the degradation of soil stiffness with increasing strains for different clay types.

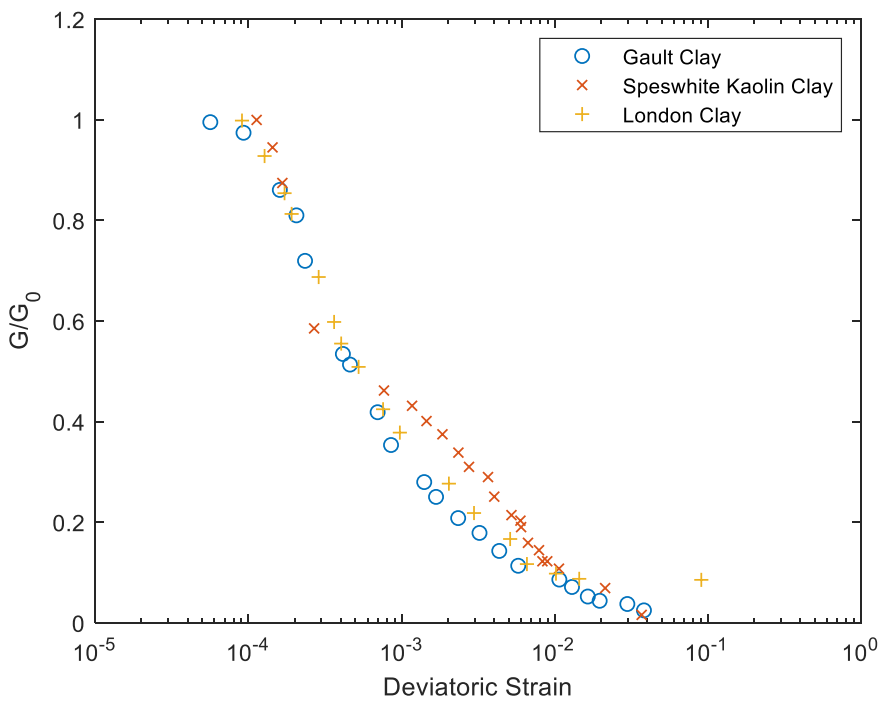

Fig. 5 Degradation of tangent with deviatoric strain (Adapted from Dasari [19]) of soil [Gunn 1993, Bolton and Whittle 1999]:

$$
G=a \varepsilon_{q}^{n}
$$


where $a=\frac{G_{0}}{\varepsilon q_{0}^{n}}$, is a constant determined empirically, $n$ describes soil nonlinearity which is equal to (-0.5) according to the experimental data analyzed by Osman et al. (2007) (Fig. 6). $\varepsilon_{q}$ represents the deviatoric strain and $\varepsilon_{q_{0}}$ is the 211 maximum deviatoric strain with linear elastic behavior which is equal to $10^{-5}$. The soil stiffness $G$ is estimated by calculating strain at each location followed by the power law.

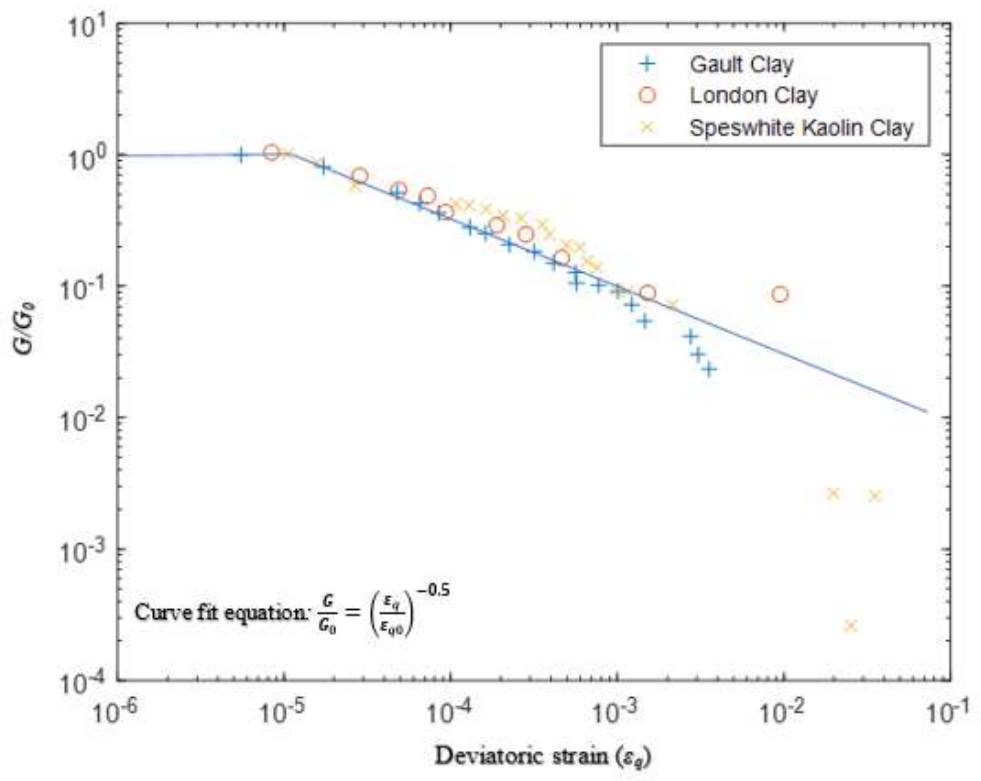

213

Fig. 6 Logarithmic scale of degradation of tangent stiffness with strain level (Adapted from Osman et al. 2007 after Dasari 1996)

\section{Iterative Solution Methodology}

216 The pile deflection equation can be solved when the soil and geometry related parameters $k, C$ and $m$ are known;

217 however, these parameters depend on the unknown dimensionless soil function $\phi$, which can be estimated by 218 calculating $\gamma_{1}$ and $\gamma_{2}$. Soil displacement is obtained when the initial numbers of these values $\gamma_{1}$ and $\gamma_{2}$, are inserted 219 into Equation 19, from which the parameters $k, C$ and $m$ are obtained as a result of the pile displacement. New values 220 of $\gamma_{1}$ and $\gamma_{2}$ (Equations (20) and (21)) are determined and then inserted into Equation 19 to evaluate $\phi$, then $v$, so an iteration technique is needed to obtain the condition $\frac{\gamma_{\text {old }}-\gamma_{\text {new }}}{\gamma_{\text {old }}}>0.001$. This iterative solution methodology (Fig. 7)

222 is used as input to the software MATLAB R2019a to obtain the pile head displacements. 


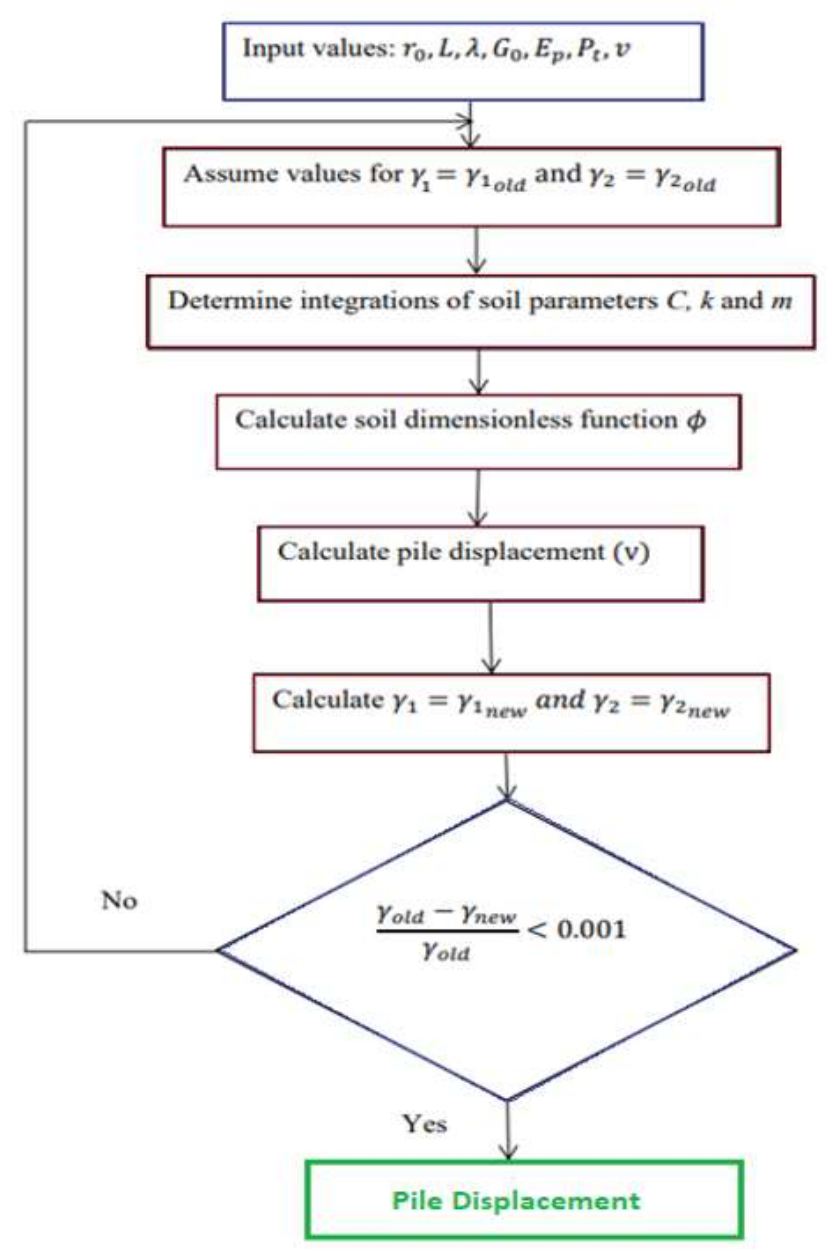

Fig. 7 Flowchart of the iterative solution scheme

229 The present study makes a comparison of Russo's field test data to validate the superiority of the energy-based method 230 for non-linear elastic soil over the linear elastic solution of Salgado et al. 2007. Russo (2004) outlined the case history 231 of micro piles used for underpinning a historical building in Naples, Italy. A load test was carried out on a micro pile, $2320.2 \mathrm{~m}$ in diameter and $19 \mathrm{~m}$ in length with an elastic modulus of $27 \mathrm{GPa}$, as shown in Fig. 8. The pile and soil 233 characteristics used in the present study are adopted from the published literature by Seo and Prezzi (2007). 


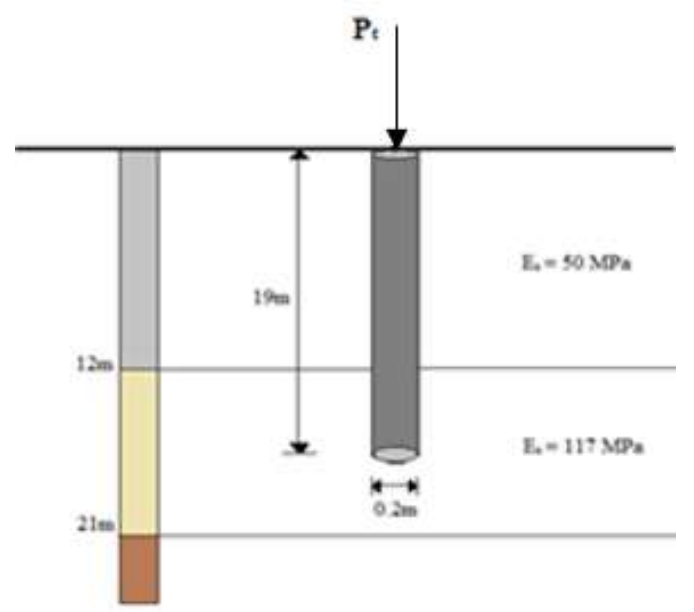

236 The soil characteristics are given below:

Table 1 Soil characteristics at the site

\begin{tabular}{|c|c|c|c|c|}
\hline Soil Characteristics & Soil thickness $(m)$ & Young's Modulus, $E(M P a)$ & Shear Modulus, $G_{0}(M P a)$ & Poisson's Ratio \\
\hline Layer 1 & 12 & 50 & 35 & 0.3 \\
\hline Layer 2 & 9 & 117 & 18 & 0.3 \\
\hline
\end{tabular}

238

239 The power law equation (Equation (24)) is used to model the soil stiffness as a function of strain to account for the

240 soil non-linearity. In Equation (24), $a=\frac{G_{0}}{\varepsilon q_{0}^{n}}$, is a constant value and the value of $G_{0}$ for each layer is taken as reported

241 from Table 1, $\varepsilon_{q}$ donates deviatoric strain, $\varepsilon_{q_{0}}$ is the maximum deviatoric strain with linear elastic behavior which is

242 equal to $10^{-5}$ and $n$ represents a constant. The present study uses the published data for $n=-0.5$ proposed by Osman

243 et al. (2007).

244 A series of axial loads were applied to the pile head to obtain the corresponding vertical displacements. Fig. 9 compares

245 the pile displacements from the energy-based method with the field data and the linear elastic solution. 


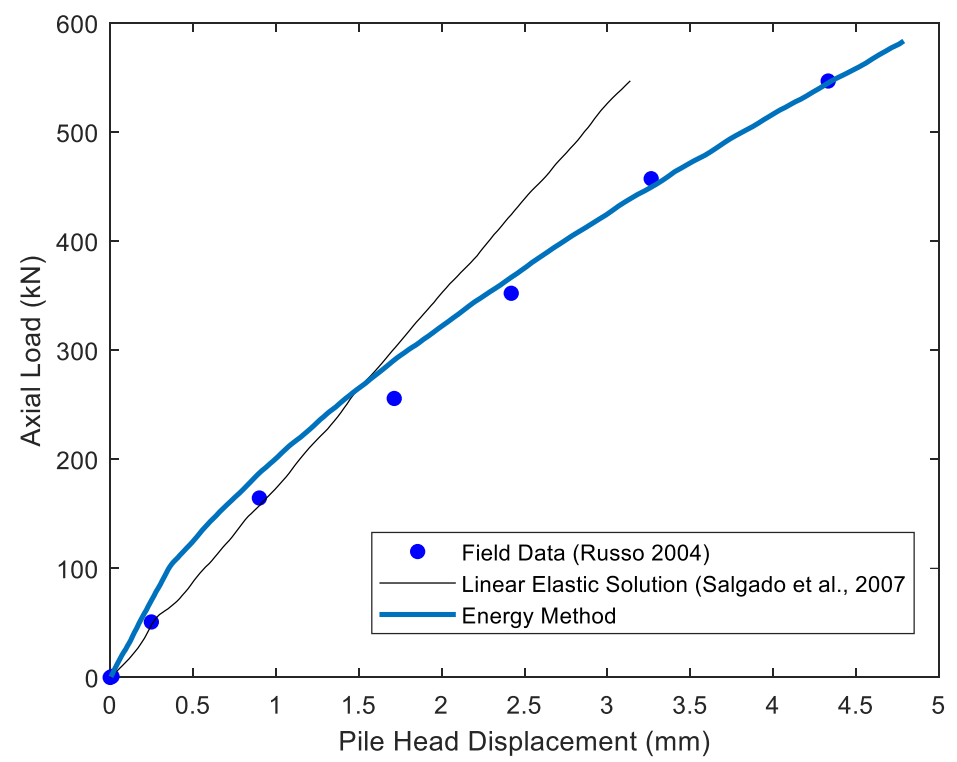

Fig. 9 Response of the pile due to axial load

248 The predicted pile displacements in the present study are in good agreement with the field data. It can be seen that the 249 pile displacements from the present study and the published field data are greater than the computed values based on 250 linear elastic soil solution when the axial load in the pile exceeds $300 \mathrm{kN}$.

(b) “An instrumented driven pile in Dublin boulder clay": Farrell et al. (1998)

252 Farrell et al. (1998) conducted field experiments with an instrumented tubular steel pile driven into Dublin boulder 253 clay (DBC). The aim of these experiments, undertaken as a part of a research project at Trinity College Dublin (TCD), 254 was to improve the understanding of the factors governing the axial load capacity of driven piles in hard glacial tills.

255 Soil Characteristics:

256 The area's geotechnical characteristics was investigated by various researchers [Skipper et al. 2005, Long and Menkiti 257 2007, Farrell et al. 1988, Gavin et al. 2008]. The area of the outcrop of the DBC is indicated in Fig. 10 [Long and 258 Menkiti 2007]. The sketch map is not intended to be a definite geological map of Dublin but aims to show the location 259 of the study sites and the prevalence of DBC in the area. 


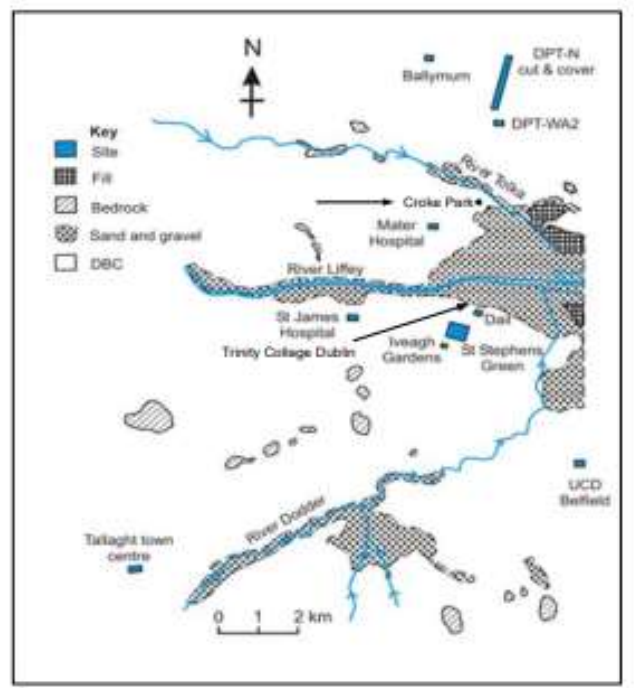

Fig. 10 Location sites in Dublin (Long and Menkiti 2007)

262 A detailed description of the geology at the test site is given by Skipper et al. (2005) whereas a brief summary is given 263 by Long and Menkiti (2007). The geology of the area as investigated by [Long and Menkiti 2007], classifies the soil 264 layers into four categories: Upper Brown Boulder Clay (UBrBC), Upper Black Dublin Boulder Clay (UBkBC), Lower 265 Brown Dublin Boulder Clay (LBrBC), and Lower Black Dublin Boulder Clay. An undrained triaxial compression test was conducted in order to determine the undrained shear strength of the black boulder clay, which was $450 \mathrm{kPa}$. Moreover, Phillips and Lehane (1998) and Long and Menkiti (2007), determined that the average undrained strength 268 for upper brown boulder clay $(\mathrm{UBrBC})$ was $100 \mathrm{kPa}$, and between $350 \mathrm{kPa}$ and $600 \mathrm{kPa}$ for upper black boulder clay 269 (UBkBC). In the present study, an average undrained strength of $450 \mathrm{kPa}$ was adopted. Lame's constant and shear 270 modulus vary in the nonlinear soil and pile responses are calculated by assuming the soil as homogenous. Long and 271 Menkiti (2007) reported $G_{0}=98 \mathrm{MPa}$ for the first layer and $G_{0}=83 \mathrm{MPa}$ for the second layer. A single 'operational' 272 value of $E_{u}=100 \mathrm{MPa}$ is used, as derived from field observations [Farrell et al. 1995a]. The degradations of soil 273 stiffness for UBrBC and UBkBC based on the present study are shown in Fig. 11 and Fig. 12 respectively. The initial 274 soil stiffness used in the calculations is based on Long's study, and also calculated using the power law relation in 275 Equation (24). The present study uses the published data for $n=-0.5$ proposed by Osman et al. (2007). This value is 276 in good agreement with published values for clay by Long and Menkiti (2007). 


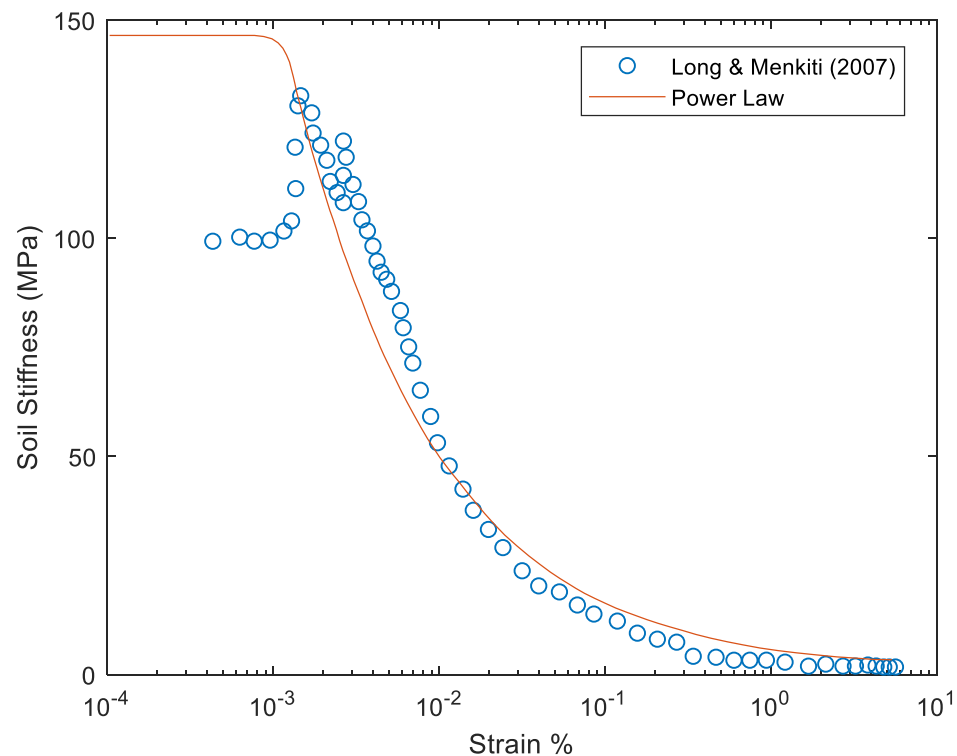

Fig. 11 Variation of soil stiffness with strains for Upper Brown Boulder Clay

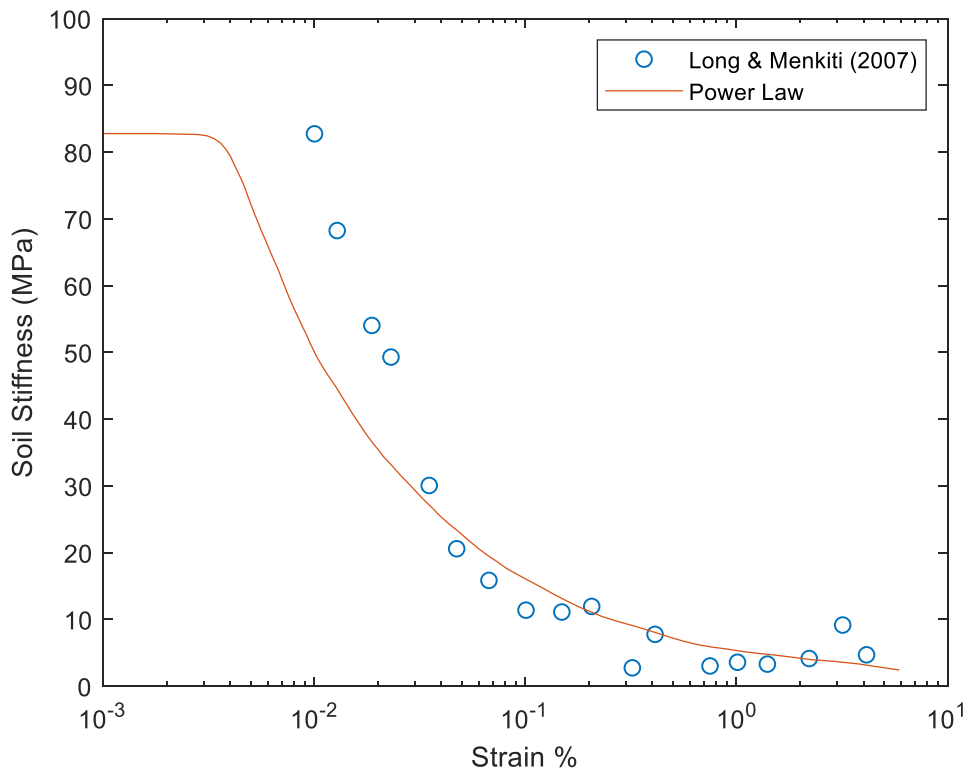

Fig. 12 Variation of soil stiffness with strains for Upper Black Boulder Clay

Pile Characteristics:

282 A steel closed-end tubular driven pile, $0.273 \mathrm{~m}$ in diameter and $7.5 \mathrm{~m}$ in length, was embedded in the boulder clay

283 (Fig.13). The thickness of the pile was $10 \mathrm{~mm}(0.01 \mathrm{~m})$ (Fig. 11). A flat $20 \mathrm{~mm}(0.02 \mathrm{~m})$ thick, $0.273 \mathrm{~m}$ diameter steel 284 disc was used to close the pile base. 


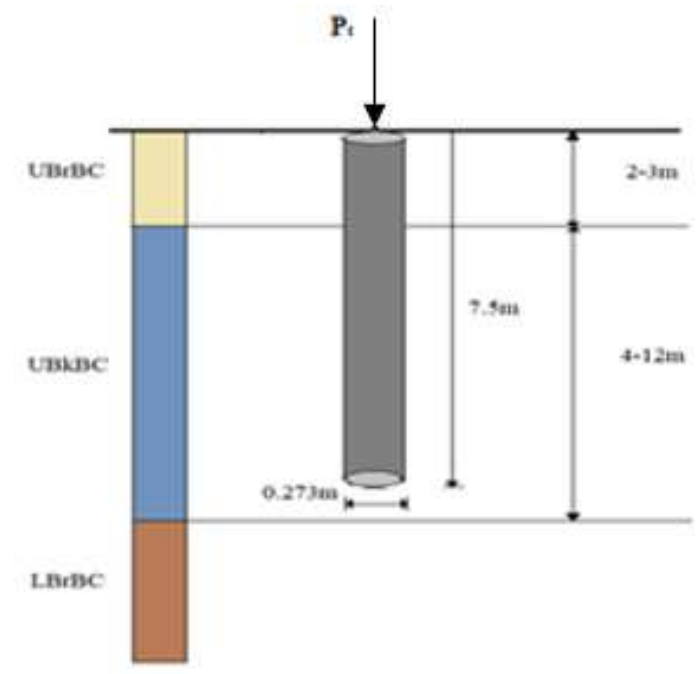

Fig. 13 Pile Profile at TCD in Dublin

287 A series of axial loads were applied to the pile in order to obtain the pile-soil deformation. The field test results are and predicted pile head deformations.

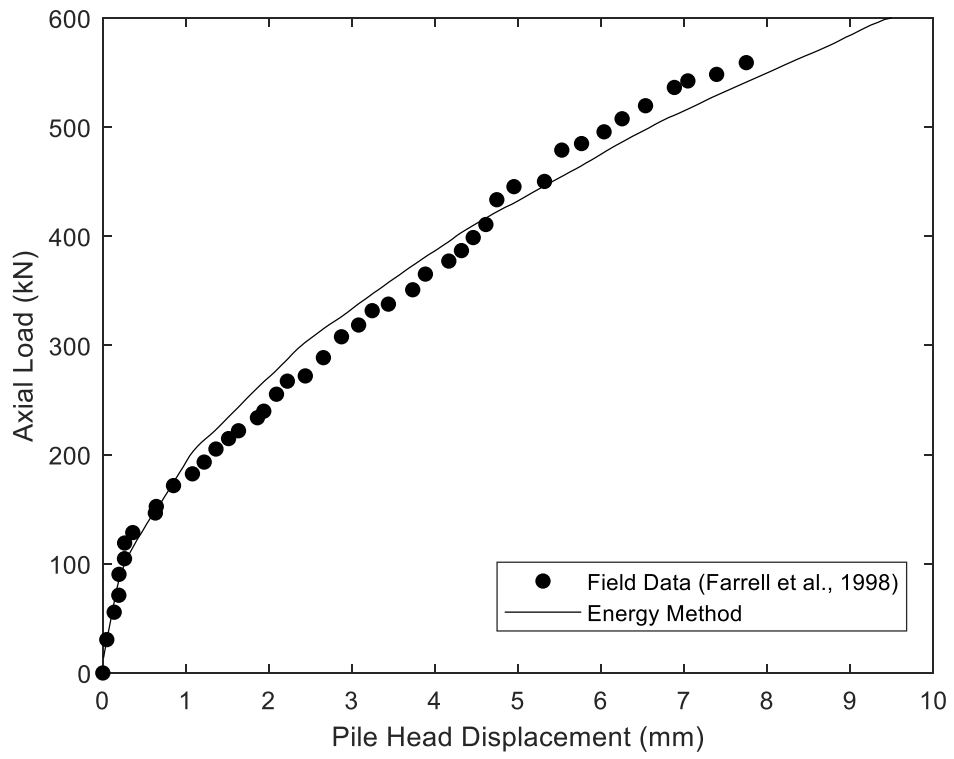

Fig. 14 Response of the head of the axially loaded pile

292 Fig. 14 shows that the energy-based method predicts the pile head displacements which are in good agreement with 293 the field measurements. 
295 A FEA was conducted using the software ANSYS Workbench 2019 R3 for the Soil-Pile problem as discussed in the 296 above section. A static structural analysis was chosen and the input data for the soil characteristics was taken from 297 Long and Menkiti (2007). The pile characteristics were added according to the steel pile used by Farrell et al. (1998).

298 The soil non-linearity was considered based on the actual soil stress-strain curves reported by Long and Menkiti (2007) 299 for each soil layer (as shown in Fig. 15 and Fig. 16).

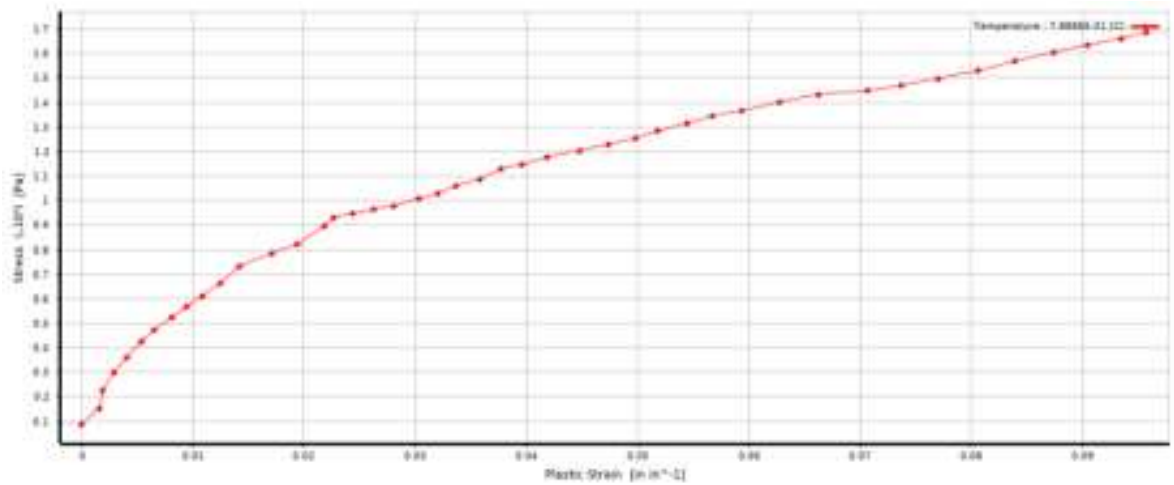

Fig. 15 Input Stress-strain relationship curve of soil layer 1 for the software ANSYS

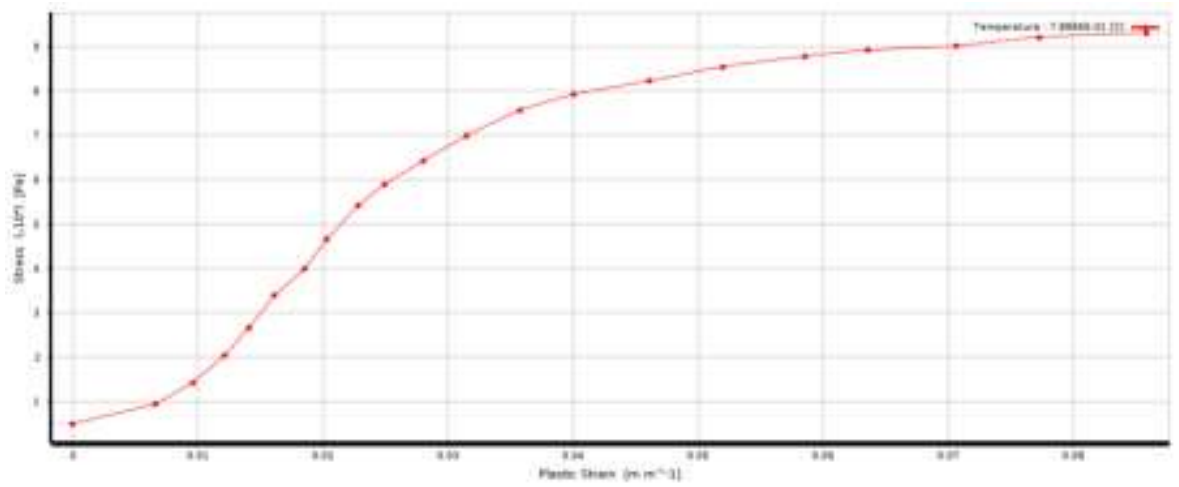

Fig. 16 Input Stress-strain relationship curve of soil layer 2 for the software ANSYS

304 The soil block's length was chosen as 15 times the pile diameter (15D) and the depth was according to the depth of 305 each soil layer. The soil block was fixed at the bottom and free on the surroundings. The discretized Finite Element Model (FEM) with a coarse mesh of 6978 nodes and 2039 elements is shown in Fig. 17. A Directional Deformation along the $Z$-axis is used to calculate the displacements of pile head for the respective force applied. 


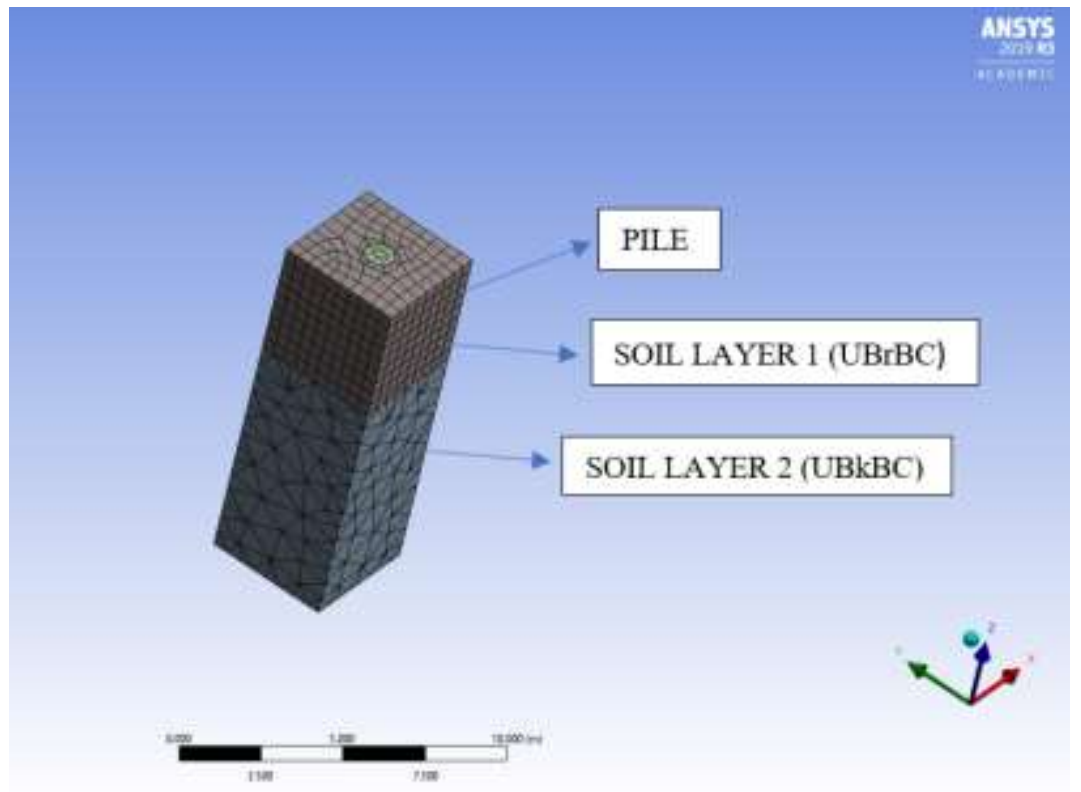

Fig. 17 A mesh representation of the FEM Model (ANSYS 2019 R3)

310 Fig. 18 compares the pile head displacements obtained by energy-based method and the FEM Analysis. Both the

311 methods underestimate the pile head displacements when compared to the field measured values. However, the

312 displacements obtained by energy-based method are in good agreement upto $20 \mathrm{kN}$. On the other hand, the FEA gives

313 displacements close to field measured values only upto $10 \mathrm{kN}$ and beyond that the displacements appear to be smaller.

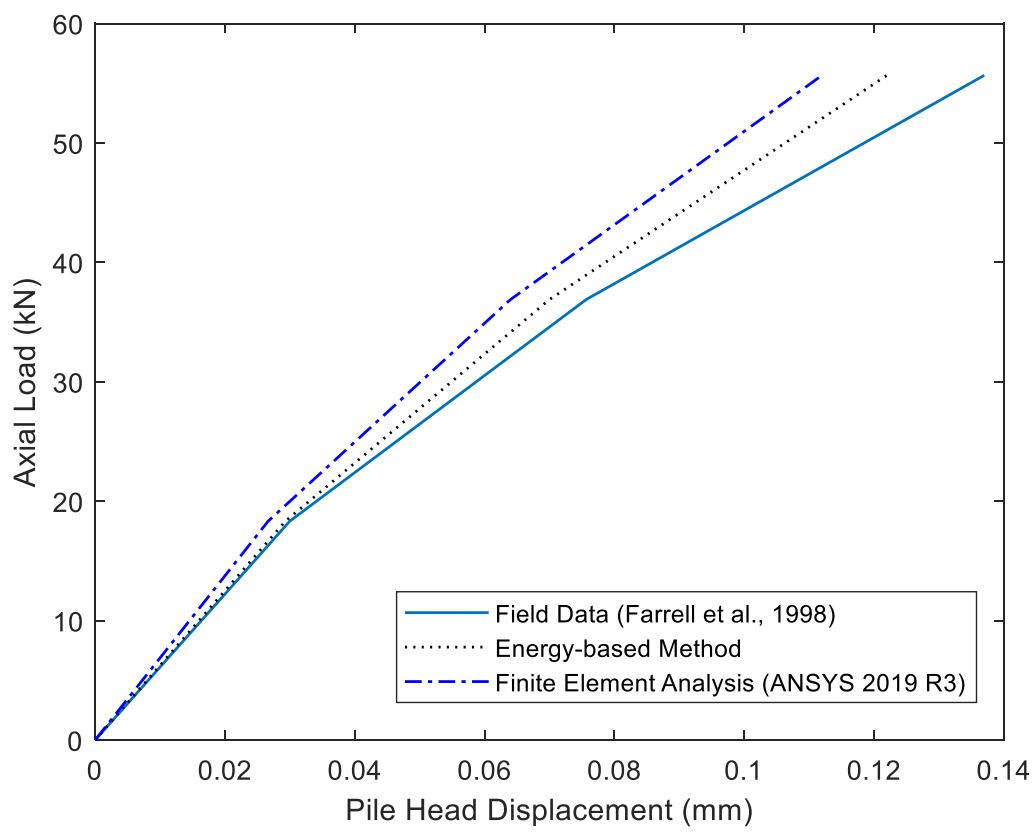


317 The beam-on-nonlinear-foundation approach ( $p-y$ method) has been used extensively used to understand the pile318 displacement responses. This approach has the limitation of representing the surrounding soil using nonlinear springs 319 requiring realistic user specified soil characteristics of $p-y$ curves which do not represent the three-dimensional pile320 soil interaction. Several researchers have studied the pile responses using numerical methods including boundary 321 element method, finite element method and finite difference method. Although the finite element method using 322 appropriate soil constitutive relationship, elements and domains for the soil and pile gives realistic results, the method 323 requires enormous computation time and the resources required for such an analysis stands out as a major limitation.

324 This gives rise to the need for a more efficient method which has both the strength of a rigorous three-dimensional 325 nonlinear approach for the pile-soil interaction and potentials for obtaining a faster computational effort. The present 326 study presents an analytical solution based on an energy method (discretized continuum approach) to predict pile soil 327 displacements, where the soil is assumed to be non-linear elastic (soil parameters vary in radial, tangential and vertical 328 directions). The analysis was conducted on an axially (vertical) loaded pile embedded in multilayered soil. Governing 329 equations for pile and soil have been obtained by applying the variational principle to the potential energy which are then solved using the software MATLAB R2019a. Comparisons have been made with the published field data and the

331 finite element method. It is observed that the energy-based method described in this study is in good agreement with 332 the field data when compared to the linear elastic solution that does not consider the soil non-linearity. The FEA has 333 been carried out using the software ANSYS Workbench 2019 R3. The soil non-linearity is considered by inserting the 334 stress-strain curves of each soil layer available from the published literature. It is observed that the results obtained 335 from the energy-based method are in better agreement with the field measured values than those obtained from the 336 FEA. The study illustrates the superior advantage of the fast solutions obtained by the energy-based method over the 337 finite element method.

\section{Conclusions and Future work}

339 The present energy-based method considering the non-linear response of the soil gives a good approximation of the 340 field data when compared to the linear elastic solution and the finite element method. The main goal of this study is 
341 to extend the same approach to laterally loaded pile and to the combined action of lateral and axial loading on the pile.

342 Furthermore, the same approach will be extended to study the response of the soil to group piles.

343

344

345

346

347

348

349

350

351

352

353

354

\section{References}

1. Asik, M. Z and Vallaban, C. V. G. (2001). A simplified model for the analysis of machine foundations on non-saturated elastic and linear soil layer. Journal of Computers and Structures, 79, pp 2717-2726.

2. Atkinson, J. H and Sallfors, G. (1991). Experimental determination of stress-strain-time characteristics in laboratory and in situ tests. Proceedings of the 10th European Conference on Soil Mechanics and Foundation Engineering, Florence, 3, pp 915-956.

3. Atkinson, J. H. (2000). Non-linear soil stiffness in routine design. Géotechnique, 50 (5), pp 478-508.

4. Banerjee, P. K and Davies, T. G. (1978). The behaviour of axially and laterally loaded single piles embedded in non-homogeneous soils. Géotechnique, 28(3), pp 309-326.

5. Basack, S and Dey, S. (2011). Pile subjected to lateral cycle loading in sand. Proceedings of the Indian Geotechnical Conference. Paper No. N343.

6. Basack, S and Dey, S. (2012). Influence of relative pile-soil stiffness and load eccentricity on single pile response in sand under lateral cyclic loading. Geotechnical and Geological Engineering, an International Journal, springer, 30(2), pp 737-751.

7. Basu, D and Salgado, R. (2007). Elastic analysis of laterally loaded pile in multi-layered soil. Journal of Geomechanics and Geoengineering. 2 (3), pp 183-196.

8. Basu, D., Prezzi, M., Salgado, R and Chakraborty, T. (2008). Settlement analysis of piles with rectangular cross sections in multi-layered soils. Computers and Geotechnics Journal, 35, pp 563-575.

9. Basu, D., Salgado, R and Prezzi, M. (2008). Analysis of laterally loaded piles in multilayered soil deposits. Publication FHWA/IN/JTRP-2008/23. Joint Transportation Research Program, Indiana. Department of Transportation and Purdue University, West Lafayette, Indiana. doi: 10.5703/1288284313454.

10. Basu, D., Salgado, R and Prezzi, M. (2009). A continuum- based model for analysis of laterally loaded piles in layered soils. Géotechnique, 59 (2), pp 127-140.

11. Bolton, M. D and Whittle, R. W. (1999). A non-linear elastic perfectly plastic analysis for plane strain undrained expansion. Géotechnique, 49 (1), pp 133-141. 
12. Bolton, M. D., Sun, H. W and Britto, A. M. (1993). Finite element analyses of bridge abutments of firm clay. Computers and Geotechnics Journal, 15, pp 22-245.

13. Bransby, M. F. and Springman, S. M. (1996). 3D finite element modelling of pile groups adjacent to surcharge loads. Journal of Computers and Geotechnics, 19 (4), pp 301-324.

14. Bransby, M. F. (1999). Selection of p-y curves for the design of single laterally loaded piles. International Journal for Numerical and Analytical Methods in Geomechanics, 23(15), pp 1909-1926.

15. Brown, D. A., Shie, C. and Kumar, M. (1989). P-y curves for laterally loaded piles derived from threedimensional finite element model. Proceeding of the 3rd International Symposium on Numerical Models in Geomechanics (NUMOG III), Niagara Falls, pp 683- 690.

16. Budhu, M and Davies, T. G. (1988). Nonlinear analysis of laterally loaded piles in cohesionless soil. Canadian Geotechnical Journal, 24, pp 289-296.

17. Burland, J. B. (1990). 30th Rankine lecture- on the compressibility and shear-strength of natural clays, Géotechnique, 40(3), ISSN: 0016-8505, pp 329-378.

18. Carter, J. P and Kulhawy, F.H. (1992). Analysis of laterally loaded shafts in rock. Journal of Geotechnical Engineering, 118(6), pp 839-855.

19. Dasari, G. R. (1996). Modelling the variation of soil stiffness during sequential construction. PhD thesis, University of Cambridge.

20. Drnevich, V. P and Massarsch, K. R. (1979). Sample disturbance and stress-strain behavior. ASCE Journal of Geotechnical Engineering Division, 105 (GT9), pp 1001-1016.

21. Farrell, E. R., Bunni, N. G and Mulligan, J. (1988). The bearing capacity of Dublin black boulder clay. Transactions of the Institution of Engineers of Ireland, 112, pp 77-104.

22. Farrell, E. R., Coxon, P., Doff, D. H and Priedhomme, L. (1995a). The genesis of brown boulder clay of Dublin. Quarterly Journal of Engineering Geology, 28, pp 143-152.

23. Farrell, E., Lehane, B and Loopy, M. (1998). An instrumented driven pile in Dublin boulder clay. Journal of the Geotechnical Engineering Division, 131, pp 233-241.

24. Gavin, K., Cadogan, D and Towmey, L. (2008). Axial resistance of CFA piles in Dublin Boulder Clay. Proceeding of the Institution of Civil Engineers, Geotechnical Engineering, 161 (GE4), pp171-180. 
25. Georgiadis, K., Sloan, S. W and Lyamin, A. V. (2013). Undrained limiting lateral soil pressure on a row of piles. Journal of Computers and Geotechnics, 54, pp 175-184.

26. Gunn, M. J. (1992). The prediction of surface settlement profiles due to tunnelling. Predictive soil mechanics, Proceedings of the Wroth Memorial Symposium, Oxford, pp 304-316.

27. Gunn, M. J. (1993). The prediction of surface settlement profiles due to tunneling, Predictive soil mechanics, Houlsby and Schofield (eds.), Proceedings of the Wroth Memorial Symposium, Thomas Telford, London, pp 304-314.

28. Haldar, S and Sivakumar Babu, G. L. (2012). Response of vertically loaded pile in clay: a probabilistic study. Journal of Geotechnical and Geological Engineering, 30(1), pp 187- 196.

29. Hardin, B. O and Drnevich, V. P. (1972). Shear modulus and damping in soils: design equations and curves. Journal of the Soil Mechanics and Foundations Division, American Society of Civil Engineers, 98(SM 7), pp 667-692.

30. Hardin, B. O. (1978). The nature of the stress-strain behaviour of soils. Earthquake Engineering and Soil Dynamics, American Society of Civil Engineers, 1, pp 3-9.

31. Hashem-ali, Salma, Fidel (2014) Analytical methods for predicting load-displacement behavior of piles, Durham theses, Durham University. Available at Durham E-Theses Online: http://etheses.dur.ac.uk/10918/

32. Houlsby, G. T and Wroth, C. P. (1991). The variation of shear modulus of a clay with pressure and over consolidation ratio. Journal of Soils and Foundations, 31 (3), pp 138-143.

33. Jardine, R. J., Symes, M. J and Burland, J. B. (1984). The measurement of soil stiffness in the triaxial apparatus. Géotechnique, 34 (3), pp 323-340.

34. Klar, A and Frydman, S. (2002). Three-dimensional analysis of lateral pile response using two-dimensional explicit numerical scheme. Journal of Geotechnical and Geoenvironmental Engineering, American Society of Civil Engineers, 128 (9), pp 775-784.

35. Koutsoftas, D. C and Ladd, C. C. (1985). Design strengths for an offshore clay. Journal of the Soil Mechanics and Foundations Division, American Society of Civil Engineers, 111 (3), pp 337-355.

36. Kulhawy, F. H and Mayne, P. W. (1990). Manual on estimating soil properties for foundation design, Report No. EL-6800, Electric Power Research Institute, Palo Alto, CA. 
37. Lee, K-M and Xiao, Z. R. (1999). A new analytical model for settlement analysis of a single pile in multilayered soil. Journal of Soils and Foundations, 39(5), pp 131-143.

38. Lo Presti, D. C. F., Jamiolkowski, M., Oronzo, P and Cavallaro. (1996). Rate and creep effect on the stiffness of soils. Poceeding of the Measuring and Modeling Time Dependent Soil Behavior, pp 166-180.

39. Long, M and Menkiti, C. O. (2007). Geotechnical properties of Dublin boulder clay. Géotechnique, 57 (7), pp 595-611.

40. Ng, C. W. W and Zhang, L.M. (2001). Three-dimensional analysis of performance of laterally loaded sleeved piles in sloping ground. Journal of Geotechnical and Geoenvironmental Engineering, American Society of Civil Engineers, 127 (6), pp 499-509.

41. Osman, A. S., White, D. J., Britto A. M and Bolton, M. D. (2007). Non-linear displacement of shallow foundations on undrained clay. Géotechnique, 57(9), pp 729-737.

42. Osman, A. S., White, D. J., Britto, A. M and Bolton, M. D (2007). Simple prediction of the undrained displacement of a circular surface foundation on non-linear soil. Géotechnique, 57 (9), pp 729-737.

43. Phillips, D. M and Lehane, B. M. (1998). The lateral capacity of an instrumented pile in glacial till. Proceeding of the VII International Conference on Piling and Deep foundations, Vienna, 5, pp 131-136.

44. Poulos, H. G. (1971 b). Behavior of laterally loaded piles: II pile groups. Journal of the Soil Mechanics and

45. Poulos, H. G. (1971a). Behavior of laterally loaded piles: I-Single Piles. Journal of the Soil Mechanics and Foundation Division, American Society of Civil Engineers, 97(SM5), pp 711-731.

46. Randolph, M. F. (1981). The response of flexible piles to lateral loading. Géotechnique, 31(2), pp 247-259.

47. Russo, G. (2004). Full-scale load test on instrumented micropiles. Proceedings of the Institution of Civil Engineers: Geotechnical Engineering, 157(3), pp 127-135.

48. Salgado, R., Prezzi, M and Seo, H. (2007). Advanced modeling tools for the analysis of axially loaded piles, Proceedings of the International Workshop on Recent Advances in Deep Foundations (IWDPF07). Ed. by Kikuchi, Otani, Kimura and Morikawa.

49. Seo, H. and Prezzi, M. (2007). Analytical solutions for a vertically loaded pile in multilayered soil. Geomechanics and Geoengineering: An International Journal, 2 (1), pp 51-60. 
50. Seo, H., Basu, D., Prezzi, M and Salgado, R. (2009). Load-settlement response of rectangular and Circular piles in multilayered soil. Journal of Geotechnical and Geoenvironmental Engineering, 135 (3), pp 420-430.

51. Skipper, J., Follet, B., Menkiti, C. O, Long, M. and Clarke-Hughes, J. (2005). The engineering geology and characterisation of Dublin Boulder Clay. Q. J. Engng Geol. Hydrogeol. 38, No. 2, 171-187.

52. Trochanis, A.M., Bielak, J. and Christiano, P. (1991). Three-dimensional nonlinear study of piles. Journal of Geotechnical Engineering, American Society of Civil Engineers, 117 (3), pp 429-447.

53. Vallabhan, C. V. G. and Das, Y. C. (1991a). Modified Vlasov model for beams on elastic foundations. Journal of Geotechnical Engineering, American Society of Civil Engineers, 117(6), pp 956-966.

54. Vallabhan, C.V.G. and Mustafa, G. (1996). A new model for the analysis of settlement of drilled piers. International Journal of Numerical and Analytical Methods in Geomechanics, 20, pp 143-152.

55. Verruijt, A. and Kooijman, P. A. (1989). Laterally Loaded Piles in a Layered Elastic Medium. Géotechnique, 39(1), pp 39-46.

56. Vlasov, V. Z and Leont'ev, N. N. (1966). Beams, plates and shells on elastic foundations. Jerusalem: Israel Program for Scientific Translations.

57. Vucetic, M. (1994). Cyclic threshold shear strains in soils. Journal of Geotechnical and Geoenvironmental Engineering, 120 (12), pp 2208-2228.

58. Yamashita, S., Hori, T. and Suzuki, T. (2003). Effects of fabric anisotropy and stress condition on small strain stiffness of sands. Proceedings of the Deformation Characteristics of Geomaterials, 1, pp 187-194. (Proc. Lyon), Swets and Zeitlinger, Lisse. 